\title{
Warfarin Management and Outcomes in Patients with Nonvalvular Atrial Fibrillation Within an Integrated Health Care System
}

\author{
JaeJin An, BPharm, PhD; Fang Niu, MS; Chengyi Zheng, PhD; Nazia Rashid, PharmD, MS: \\ Robert A. Mendes, MD; Diana Dills, MD; Lien Vo, PharmD, MPH; Prianka Singh, PharmD; \\ Amanda Bruno, PhD, MPH; Daniel T. Lang, MD; Paul T. Le, PharmD; \\ Kristin P. Jazdzewski, PharmD; and Gustavus Aranda, Jr., PharmD, MS
}

\begin{abstract}
BACKGROUND: Warfarin is a common treatment option to manage patients with nonvalvular atrial fibrillation (NVAF) in clinical practice. Understanding current pharmacist-led anticoagulation clinic management patterns and associated outcomes is important for quality improvement; however, currently little evidence associating outcomes with management patterns exists.
\end{abstract}

OBJECTIVES: To (a) describe warfarin management patterns and (b) evaluate associations between warfarin treatment and clinical outcomes for patients with NVAF in an integrated health care system.

METHODS: A retrospective cohort study was conducted among NVAF patients with warfarin therapy between January 1, 2006, and December 31, 2011, using Kaiser Permanente Southern California data, and followed until December 31, 2013. Management patterns related to international normalized ratio (INR) monitoring, anticoagulation clinic pharmacist intervention (consultation), and warfarin dose adjustments were investigated along with yearly attrition rates, time-in-therapeutic ranges (TTRs), and clinical outcomes (stroke or systemic embolism and major bleeding). Descriptive statistics and multivariable Cox proportional hazard models were used to determine associations between TTR and clinical outcomes.

RESULTS: A total of 32,074 NVAF patients on warfarin treatment were identified and followed for a median of 3.8 years. About half (49\%) of the patients were newly initiating warfarin therapy. INR monitoring and pharmacist interventions were conducted roughly every 3 weeks after 6 months of warfarin treatment. Sixty-three percent of the study population had $\geq 1$ warfarin dose adjustments with a mean (SD) of 6.7 (6.3) annual dose adjustments. Warfarin dose adjustments occurred at a median of 1 day (interquartile ranges [IQR] 1-3) after the INR measurement. Yearly attrition rate was from $3.3 \%$ to $6.3 \%$ during the follow-up, and median (IQR) TTR was $61 \%$ (46\%$73 \%$ ). Patients who received frequent INR monitoring ( $\geq 27$ times per year), pharmacist interventions ( $\geq 24$ times per year), or frequently adjusted warfarin dose ( $\geq 11$ times per year) consistently showed poor TTRs (mean TTR for the highest quartiles was $45.3 \%-48.3 \%$ ). A higher TTR was associated with a lower risk of clinical outcomes regardless of frequency of INR monitoring, pharmacist interventions, or number of dose adjustments. Patients whose TTRs were $<65 \%$, even with frequent pharmacist interventions, had similar stroke or systemic embolism event rates, as compared with patients with TTRs $<65 \%$ and less frequent interventions ( 1.88 vs. 1.54 stroke or systemic embolism rates per 100 person-years, respectively, $P=0.78$ ). The lowest TTR quartile $(<46 \%)$ was associated with a 3 times higher risk of stroke or systemic embolism (hazard ratio $[\mathrm{HR}]=3.19,95 \% \mathrm{Cl}=2.71-3.77$ ) and a 2 times higher risk of major bleeding ( $\mathrm{HR}=2.10,95 \% \mathrm{Cl}=1.96-2.24)$ compared with the highest TTR quartile ( $\geq 73 \%)$.

CONCLUSIONS: Despite close monitoring with timely warfarin dose adjustments, there were still a substantial number of challenging patients whose TTRs were suboptimal despite a higher number of pharmacist interventions. These patients eventually experienced more stroke or systemic embolism and bleeding events among NVAF patients managed by anticoagulation clinics. New individualized treatment or management strategies for patients who are not able to reach optimal therapeutic ranges are necessary to improve outcomes.

\section{J Manag Care Spec Pharm. 2017;23(6):700-12}

Copyright $\odot 2017$, Academy of Managed Care Pharmacy. All rights reserved.

\section{What is already known about this subject}

Pharmacist-managed anticoagulation services are associated with an improved time-in-therapeutic range (TTR).

Maintaining optimal levels of TTR is important to minimize stroke or systemic embolism and bleeding outcomes for warfarin patients.

\section{What this study adds}

Close monitoring with timely warfarin dose adjustments and low attrition rates were found in patients with nonvalvular atrial fibrillation managed by pharmacist-led anticoagulation clinics. Regardless of frequency of pharmacist intervention, patients with low TTR experienced more strokes or systemic embolisms and bleeding events.

Potentially nonadherent patients who did not receive frequent international normalized ratio monitoring and/or pharmacist interventions reported low TTRs, which were associated with poor clinical outcomes.

T itamin $\mathrm{K}$ antagonists, such as warfarin, have been standard treatments for stroke prevention in patients with nonvalvular atrial fibrillation (NVAF). ${ }^{1}$ Although several new classes of nonvitamin $\mathrm{K}$ antagonist oral anticoagulants are now available, warfarin is still a common treatment option in clinical practice. Warfarin was associated with a low rate of residual stroke or systemic embolism in recent clinical trials with time-in-therapeutic ranges (TTRs) between 55\% and $68 \% .^{2-4}$ However, warfarin use is limited by its narrow therapeutic range, drug-drug and drug-food interactions, and bleeding risk. ${ }^{5}$ 
The complexity of managing warfarin has led to the development of a variety of specialized care models such as patient self-management, specialized anticoagulation clinics, and pharmacist-managed services. ${ }^{6}$ To date, pharmacist-managed anticoagulation services have been an important component for improved quality of anticoagulation control, which is a common type of care model in a U.S. managed care setting. Pharmacist-managed anticoagulation clinic models point to more consistent monitoring, use of warfarin dosage adjustment algorithms, early recognition of patient risk factors, and patient education. ${ }^{6}$ Several studies have suggested that pharmacist-managed anticoagulation services are associated with improved TTR and potentially with lower hospitalization or emergency visits and thromboembolic events, compared with usual care. ${ }^{7-10}$ However, outcomes in warfarin patients still may not be optimal in these care models. Even with the introduction of these patient care models in clinical practice, approximately one third of the patients discontinued warfarin within 1 year after initiation, ${ }^{11-13}$ and TTR levels were only around $60 \%$ in the U.S. managed care setting, which is not considered optimal. ${ }^{14-15}$ Understanding current pharmacist-led anticoagulation clinic management patterns are important for quality improvement; however, currently little evidence associating outcomes with management patterns exists.

The primary objective of this study was to describe warfarin management patterns (international normalized ratio [INR] monitoring, pharmacist intervention, and warfarin dose adjustments) and outcomes (attrition rates, TTR, and stroke or bleeding events) for patients with NVAF managed by pharmacist-led anticoagulation clinics in an integrated health care system. The secondary objective was to evaluate associations between warfarin treatment (TTR levels and/or pharmacist intervention) and stroke or systemic embolism and major bleeding events. These results may help identify an appropriate place for interventions to improve warfarin management in patients with NVAF.

\section{Methods}

\section{Study Design and Setting}

A retrospective, observational, cohort study was conducted. Adult patients diagnosed with atrial fibrillation (AF) —using 2 or more serial International Classification of Diseases, Ninth Revision Clinical Modification (ICD-9-CM) codes of 427.31, 30 or more days apart-in ambulatory visit or hospital records in Kaiser Permanente Southern California (KPSC) data were identified between January 1, 2006, and December 31, 2011. This study included all incident and prevalent patients with AF. The first diagnosis date was defined as the index date, and patients were followed until the end of membership, death, or the study end date of December 31, 2013, whichever occurred first. Patients aged $<18$ years at index date; without continuous health plan membership or drug benefit during the 12 months before the index date (baseline period; gaps of less than 30 days were treated as continuous membership); and individuals who had AF ablation or cardioversion procedure, valvular repair or replacement, valvular diseases, hyperthyroidism at baseline, or evidence of pregnancy at any point during the entire follow-up period were further excluded (Appendix A, available in online article). In the final study cohort, we excluded patients without any warfarin prescriptions or patients with $\leq 1$ INR measurement.

Study population was identified from KPSC databases. KPSC is a nonprofit, integrated health care delivery organization with a membership of over 4 million people in Southern California. KPSC provides integrated, comprehensive medical services through its own facilities, which include 14 hospitals, over 200 outpatient facilities, and a centralized laboratory. All aspects of care and interaction with the health care delivery system are captured in a continuously updated electronic medical record (EMR) system. Over $98 \%$ of the study population receiving warfarin treatment were participants of anticoagulation clinics led by pharmacists. The study protocol was approved by the KPSC institutional review board.

\section{INR Monitoring and Pharmacist Intervention}

Centralized laboratory data were extracted to summarize INR monitoring patterns. The number of INR monitoring tests and days between INR tests were reported. EMR data at the anticoagulation clinic were used to describe pharmacist interventions. All encounters between pharmacists and patients at the anticoagulation clinics were stored in the EMR system. Encounters mostly involved telephone counseling, and pharmacist interventions consisted of anticoagulant medication monitoring and dose adjustment, orthopedic surgery prophylaxis, anticoagulation reversal, procedure bridging, point of care education and calibration, interruption of therapy for invasive and noninvasive procedures, anticoagulant drug interaction intervention and management, triaging of anticoagulation therapy-related adverse events, and patient and provider education. The number of pharmacist interventions and days between interventions were calculated.

\section{Warfarin Dosing}

Adjustment of warfarin doses was identified by a natural language processing algorithm. Natural language processing (NLP) is a field of computational linguistics that allows computers to parse human language. ${ }^{16}$ This technique has been used to successfully identify and extract information from free-text formatted data. ${ }^{17-20}$ In a previous study, we successfully used NLP to identify low-dose aspirin use from clinical notes with high accuracy. ${ }^{21}$ With NLP, we achieved 96\% sensitivity and $99 \%$ specificity on identifying aspirin usage. In this 
study, we enhanced the NLP algorithms to identify changes in warfarin use. The first set of algorithms are similar to what we developed for the aspirin usage study. The algorithms searched explicitly documented warfarin adjustment without specific dosage information (such as "one time dose," "skip," "hold," "off," and "discontinue") or with specific dosage information (changed to a different dosage amount). A second set of NLP searched implicitly documented warfarin adjustment such as "Warfarin is insufficient," "INR out of range," "subtherapeutic INR," and "supratherapeutic INR." Seven hundred seventy-one chart notes were manually reviewed to check the validity of this algorithm. The developed NLP algorithms were applied to all clinical notes for the study cohort during the study period. The timing of dosing was also investigated by combining these NLP results with the INR laboratory test records. The closest INR measurement date before the warfarin dose adjustment was used to determine the timing of dosing. The maximum interval of 30 days was considered as relevant INR measurements to the warfarin dosing.

\section{Warfarin Attrition}

Warfarin attrition rate was determined by the percentage of patients who discontinued warfarin divided by all available warfarin patients in a given year. Warfarin discontinuation was defined using warfarin prescriptions, INR laboratory measurements, and anticoagulation clinic intervention data. The discontinuation date was defined as the earliest date among the following: (a) the most recent covered date (last refill date plus days supply) plus 80 days of grace period; (b) INR measurement date plus 80 days of grace period; or (c) date of discharge from the anticoagulation clinic program. An 80-day grace period was chosen to reflect the interpersonal variability of warfarin dosage usage. Warfarin patients are often instructed to take one half a pill 22 ; therefore, the mean days supply of a warfarin prescription at KPSC (80 days) was applied.

\section{Time-in-Therapeutic Range}

The linear interpolation method by Rosendaal et al. (1993) was used to calculate a TTR. ${ }^{23}$ The TTR is expressed as a percentage of an INR 2-3 range, given the observation time. INR tests performed during hospitalization or INR gaps greater than 80 days were not interpolated. The TTR was summarized by warfarin management patterns (the quartiles of number of INR monitoring, pharmacist interventions, and warfarin dose adjustments per year). To further investigate clinical outcomes associated with warfarin management (TTR and/or pharmacist interventions), we stratified patients based on their (a) TTR $\geq 65 \%$ vs. TTR $<65 \%$ and (b) TTR quartile. The TTR cutoff of $65 \%$ was selected, since TTRs from $65 \%$ to $70 \%$ are usually considered as good INR controls. ${ }^{15,24}$

\section{Clinical Outcomes}

The clinical outcomes of interest were stroke or systemic embolism and major bleeding events. Primary hospital discharge diagnoses of stroke (ICD-9-CM codes 430, 431, 433.x1, 434.xl, and 436.xx) or systemic embolism (ICD-9-CM codes 444.0, 444.1, 444.2x, 444.8x, 444.9, 557.x, and 593.81) were defined as a clinical outcome. Major bleeding was defined as an intracranial bleed; gastrointestinal bleed; or any other bleed (intraspinal, intraocular, pericardial, intra-articular, and intramuscular bleed) that was associated with an inpatient care episode, blood transfusion of 2 or more units of whole blood or red blood cells, decreased hemoglobin 2 grams per $\mathrm{dL}(\mathrm{g} / \mathrm{dL})$ or more, physician-guided medical or surgical treatment, or death (Appendix A). To identify decreased hemoglobin, we searched 7 days before and after the bleed diagnosis codes and determined nadir hemoglobin level. The highest hemoglobin level before the nadir level was considered as a baseline value and was compared with the nadir level. A decrease in $2 \mathrm{~g} /$ $\mathrm{dL}$ or more was considered as a major hemorrhage according to the definition published by the International Society on Thrombosis and Hemostatis. ${ }^{19}$

\section{Statistical Analyses}

Descriptive statistics such as mean, median, interquartile ranges (IQRs), and frequencies were used to report baseline characteristics and warfarin management patterns. T-tests, analysis of variances for continuous variables, and chi-square tests for categorical variables were conducted. Stroke or systemic embolism and major bleeding events were reported using percentages and crude event rates (number of events per 100 person-years). Baseline characteristics were compared between each warfarin group (TTR quartiles).

For this outcome analysis, data were censored at the earliest date of outcome (the first stroke or systemic embolism date for the stroke or systemic embolism outcome and the first major bleeding date for the bleeding outcome); end of membership; death; or the study end date. Kaplan-Meyer survival curves with log-rank tests were used to compare time-to-events between different warfarin groups. Cox proportional hazard regression models were used to compare outcomes between groups controlling for other factors. Patient demographics (age, gender, and race/ethnicity); body mass index; baseline $\mathrm{CHADS}_{2}$ score (congestive heart failure, hypertension, age 75 or higher, diabetes, and previous stroke or transient ischemic attack); comorbidities (peripheral vascular disease, cirrhosis, cardiac myopathy, and dementia); history of bleeds, myocardial infarction, and falls; and baseline medication use (periprocedural anticoagulation, antiarrythmic medications, clopidogrel, ticlopidine, prasugrel, ticagrelor, and heart rate control medications) were considered as covariates (Appendix A). These covariates were first tested from univariate analyses, and 
statistically significant variables were considered as final covariates.

The final multivariable model was created by applying a backward model selection procedure that retained those covariates with $P<0.10$. Other clinically relevant covariates $\left(\mathrm{CHADS}_{2}\right.$ score, warfarin use at baseline, and myocardial infarction) that were not significant were forced into the final model as needed. From this model, hazard ratios (HRs) with 95\% confidence intervals (CIs) were reported.

\section{Results}

A total of 32,074 NVAF patients on warfarin treatment were identified and followed for a median of 3.8 years. Table 1 shows baseline characteristics of the study population. Mean (standard deviation [SD]) age of the population was 72.2 (10.7) years, and $42.5 \%$ were female. Of the total population, $72.2 \%$ were non-Hispanic white; $12.7 \%$ were Hispanic; $8.0 \%$ were non-Hispanic black; and $7.1 \%$ had other races/ethnicity. There were $33.8 \%$ of the study population with a $\mathrm{CHADS}_{2}$ score of 2 , and $22.8 \%$ had a score of 3 ; however, $15.6 \%$ of the population had a $\mathrm{CHADS}_{2}$ score of 0 , and the remaining $27.8 \%$ had a score of 1 . About half (49.2\%) of the patients were newly initiating warfarin therapy (new warfarin users) without any warfarin prescription during the baseline period, and the other half of the population had at least 1 warfarin prescription during the baseline period (experienced warfarin users).

Baseline characteristics were compared among different TTR strata. Overall, patients in the lowest TTR group had more comorbidities and higher $\mathrm{CHADS}_{2}$ scores than patients in the highest TTR group. The TTR $<46 \%$ group had a higher proportion of those with a $\mathrm{CHADS}_{2}$ score $\geq 3(27.4 \%)$ compared with the TTR $\geq 73 \%$ group (17.4\%), whereas the TTR $<46 \%$ group had a lower proportion of patients with a $\mathrm{CHADS}_{2}$ score of 0 (14.7\%) compared with the TTR $\geq 73 \%$ group (18.4\%). The TTR $<46 \%$ group had a higher proportion of baseline bleeds, peripheral vascular disease, fall history, diabetes, congestive heart failure, and malignancy compared with the other groups.

\section{Warfarin Dosing and Natural Language Processing}

In a validation study, the NLP algorithm achieved a sensitivity of $92.5 \%$ and specificity of $98.4 \%$. Applying the NLP algorithms to the entire study population, nearly 5 million dose adjustments were identified from the EMR. When we compared all the out of INR range (INR $<2$ or INR $>3$ ) laboratory results with the dose adjustment results identified by NLP, there were $21.8 \%$ cases where no dose adjustments were identified by NLP. Most of these cases with missing dose adjustment $(76.5 \%)$ were from the lower end of INR results $(<2)$, which may be due to true no adjustment based on clinical judgement or false negative from the algorithm.

\section{Warfarin Management}

For the overall study population, INR monitoring tests were conducted roughly every week for the first 3 months and every 3 weeks after 6 months from the index date. Mean (SD) days for INR monitoring were 8.7 (7.7) for the first 3 months and 22.1 (17.8) after 6 months (months 7-18; Table 2).

Pharmacist interventions were also conducted roughly every week for the first 3 months and every 3 weeks after 6 months from the index date. Mean (SD) days between the interventions were 9.0 (7.7) for the first 3 months and 21.5 (15.8) days after 6 months (months 7-18; Table 2). The number of interventions was consistent after 6 months from the index date; mean (SD) days between the interventions were 22.3 (16.0) days during months 19-30. Sixty-three percent of the study population had at least 1 warfarin dose adjustment with a mean (SD) of 6.7 (6.3) annual dose adjustments after 6 months of warfarin therapy. Warfarin dose adjustments occurred at a median (IQR) of 1 day (1-3) after the INR measurement.

When analyzing the data separately for new and experienced warfarin users, new warfarin users received more frequent interventions during the first 3 months; these patients received an intervention roughly every week, whereas experienced warfarin users received an intervention roughly every 2 weeks during the first 3 months: mean (SD) days were 8.0 (6.3) for new users versus 14.9 (11.5) for experienced users. More frequent dose adjustments were found for new warfarin users compared with experienced warfarin users for the first 3 months: mean (SD) number of dose adjustment was 4.7 (3.7) for new users versus 2.9 (3.1) for experienced users.

\section{Warfarin Attrition}

During the 5 years of follow-up, the majority of participants (over 93\%) were continuously on warfarin therapy (Appendix B, available in online article). The rate of discontinuation was $3.3 \%$ at the end of the first year, and the rate increased to $6.3 \%$ at the end of 5 years. The rate of disenrollment from the health plan or completion of follow-up was approximately 20\%-35\% each year.

\section{Time-in-Therapeutic Ranges by Warfarin Management}

Median TTR (IQR range) during the entire follow-up period for the study population was $61.0 \%$ (46\%-73\%). The TTR among the new warfarin users was slightly lower; the median TTR was $58.7 \%$ (43.1\%-71.3\%; data not shown). In general, patients who received a higher number of INR monitoring, pharmacist interventions, or frequently adjusted warfarin dose consistently showed poor ranges of TTR (Figure 1). The mean (95\% CI) TTRs were 46.9\% (46.4\%-47.4\%) for individuals with frequent INR monitoring (fourth quartile: $\geq 27$ times per year) and $62.9 \%$ (62.5\%-63.3\%) for less frequent INR monitoring (second quartile: 14-18 times per year). The mean (95\% CI) TTRs were 48.3\% (47.8\%-48.8\%) 


\begin{tabular}{|c|c|c|c|c|c|c|c|c|c|c|c|}
\hline \multirow[b]{3}{*}{ Age, mean [SD] } & \multicolumn{10}{|c|}{ TTR Quartiles } & \multirow{3}{*}{$\begin{array}{c}P \text { Value } \\
<0.001\end{array}$} \\
\hline & \multicolumn{2}{|c|}{$\begin{array}{l}\text { TTR }<46 \% \\
(\mathrm{n}=8,435)\end{array}$} & \multicolumn{2}{|c|}{$\begin{array}{l}\text { TTR } 46 \%-60 \% \\
(\mathrm{n}=7,983)\end{array}$} & \multicolumn{2}{|c|}{$\begin{array}{l}\text { TTR } 61 \%-72 \% \\
(\mathrm{n}=7,966)\end{array}$} & \multicolumn{2}{|c|}{$\begin{array}{l}\text { TTR } \geq 73 \% \\
(\mathbf{n}=7,690)\end{array}$} & \multicolumn{2}{|c|}{$\begin{array}{c}\text { Total } \\
(\mathrm{N}=32,074) \\
\end{array}$} & \\
\hline & 71.5 & [11.9] & 72.9 & {$[10.6]$} & 72.6 & {$[10.1]$} & 71.9 & {$[10.1]$} & 72.2 & {$[10.7]$} & \\
\hline \multicolumn{11}{|l|}{ Age category, years, n (\%) } & $<0.001$ \\
\hline$<65$ & 2,185 & $(25.9)$ & 1,654 & $(20.7)$ & 1,614 & $(20.3)$ & 1,728 & $(22.5)$ & 7,181 & $(22.4)$ & \\
\hline $65-74$ & 2,415 & $(28.6)$ & 2,393 & $(30.0)$ & 2,583 & $(32.4)$ & 2,572 & $(33.4)$ & 9,963 & $(31.1)$ & \\
\hline $75-84$ & 2,822 & $(33.5)$ & 2,965 & $(37.1)$ & 2,958 & $(37.1)$ & 2,720 & $(35.4)$ & 11,465 & $(35.7)$ & \\
\hline$\geq 85$ & 1,013 & $(12.0)$ & 971 & $(12.2)$ & 811 & $(10.2)$ & 670 & $(8.7)$ & 3,465 & $(10.8)$ & \\
\hline Female, n (\%) & 3,739 & $(44.3)$ & 3,629 & $(45.5)$ & 3,422 & $(43.0)$ & 2,855 & $(37.1)$ & 13,645 & $(42.5)$ & $<0.001$ \\
\hline \multicolumn{11}{|l|}{ Race/ethnicity, n (\%) } & $<0.001$ \\
\hline Non-Hispanic white & 5,867 & $(69.6)$ & 5,796 & $(72.6)$ & 5,838 & $(73.3)$ & 5,656 & $(73.6)$ & 23,157 & $(72.2)$ & \\
\hline Hispanic & 1,135 & $(13.5)$ & 1,026 & $(12.9)$ & 992 & $(12.5)$ & 924 & $(12.0)$ & 4,077 & $(12.7)$ & \\
\hline Non-Hispanic black & 895 & $(10.6)$ & 645 & $(8.1)$ & 560 & $(7.0)$ & 451 & $(5.9)$ & 2,551 & $(8.0)$ & \\
\hline Others & 538 & $(6.4)$ & 516 & $(6.5)$ & 576 & $(7.2)$ & 659 & $(8.6)$ & 2,289 & $(7.1)$ & \\
\hline CCI score, ${ }^{\mathrm{a}}$ mean $[\mathrm{SD}]$ & 1.3 & {$[2.7]$} & 0.9 & {$[2.2]$} & 0.6 & {$[1.7]$} & 0.5 & {$[1.5]$} & 0.8 & {$[2.1]$} & $<0.001$ \\
\hline CHADS $_{2}$ scores, mean [SD] & 1.8 & {$[1.2]$} & 1.8 & {$[1.1]$} & 1.7 & {$[1.1]$} & 1.5 & {$[1.1]$} & 1.7 & [1.1] & $<0.001$ \\
\hline \multicolumn{11}{|l|}{ CHADS $_{2}$ scores, $\mathbf{n}(\%)$} & $<0.001$ \\
\hline 0 & 1,239 & $(14.7)$ & 1,117 & $(14.0)$ & 1,228 & $(15.4)$ & 1,417 & $(18.4)$ & 5,001 & $(15.6)$ & \\
\hline 1 & 2,098 & $(24.9)$ & 2,064 & $(25.9)$ & 2,308 & $(29.0)$ & 2,432 & $(31.6)$ & 8,902 & $(27.8)$ & \\
\hline 2 & 2,787 & $(33.0)$ & 2,772 & $(34.7)$ & 2,789 & $(35.0)$ & 2,502 & $(32.5)$ & 10,850 & $(33.8)$ & \\
\hline 3 or more & 2,311 & $(27.4)$ & 2,030 & $(25.4)$ & 1,641 & $(20.6)$ & 1,339 & $(17.4)$ & 7,321 & $(22.8)$ & \\
\hline \multicolumn{12}{|c|}{ Comorbid conditions or event, $\mathbf{n}(\%)$} \\
\hline Congestive heart failure & 2,088 & (24.8) & 1,806 & $(22.6)$ & 1,401 & $(17.6)$ & 1,113 & $(14.5)$ & 6,408 & $(20.0)$ & $<0.001$ \\
\hline Hypertension & 6,226 & $(73.8)$ & 5,799 & $(72.6)$ & 5,654 & $(71.0)$ & 5,218 & $(67.9)$ & 22,897 & $(71.4)$ & $<0.001$ \\
\hline Diabetes mellitus & 2,643 & $(31.3)$ & 2,347 & $(29.4)$ & 2,027 & $(25.4)$ & 1,731 & $(22.5)$ & 8,748 & $(27.3)$ & $<0.001$ \\
\hline Stroke/transient ischemic attack & 262 & $(3.1)$ & 204 & $(2.6)$ & 211 & $(2.6)$ & 155 & $(2.0)$ & 832 & $(2.6)$ & $<0.001$ \\
\hline Peripheral vascular disease & 1,007 & $(11.9)$ & 860 & $(10.8)$ & 575 & $(7.2)$ & 499 & $(6.5)$ & 2,941 & $(9.2)$ & $<0.001$ \\
\hline Myocardial infarction & 260 & $(3.1)$ & 177 & $(2.2)$ & 139 & $(1.7)$ & 100 & $(1.3)$ & 676 & $(2.1)$ & $<0.001$ \\
\hline Cardiomyopathy & 813 & $(9.6)$ & 697 & $(8.7)$ & 615 & $(7.7)$ & 507 & $(6.6)$ & 2,632 & $(8.2)$ & $<0.001$ \\
\hline Liver cirrhosis & 57 & $(0.7)$ & 31 & $(0.4)$ & 23 & $(0.3)$ & 21 & $(0.3)$ & 132 & $(0.4)$ & $<0.001$ \\
\hline Dementia & 91 & $(1.1)$ & 63 & $(0.8)$ & 38 & $(0.5)$ & 43 & $(0.6)$ & 235 & $(0.7)$ & $<0.001$ \\
\hline Bleeding & 719 & $(8.5)$ & 680 & $(8.5)$ & 603 & $(7.6)$ & 487 & $(6.3)$ & 2,489 & $(7.8)$ & $<0.001$ \\
\hline Fall & 426 & $(5.1)$ & 333 & $(4.2)$ & 257 & $(3.2)$ & 215 & $(2.8)$ & 1,231 & (3.8) & $<0.001$ \\
\hline Malignancy & 1,054 & $(12.5)$ & 948 & $(11.9)$ & 858 & $(10.8)$ & 765 & $(9.9)$ & 3,625 & $(11.3)$ & $<0.001$ \\
\hline Baseline warfarin use, $\mathbf{n}(\%)$ & 3,363 & $(39.9)$ & 4,088 & $(51.2)$ & 4,425 & $(55.5)$ & 4,424 & $(57.5)$ & 16,300 & $(50.8)$ & $<0.001$ \\
\hline Warfarin start within 2 months & 6,924 & $(82.1)$ & 7,030 & $(88.1)$ & 7,181 & $(90.1)$ & 6,944 & $(90.3)$ & 28,079 & $(87.5)$ & $<0.001$ \\
\hline \multicolumn{12}{|c|}{ Other pharmacologic treatment, $\mathbf{n}(\%)$} \\
\hline Heart rate control & 6,200 & $(73.5)$ & 6,212 & $(77.8)$ & 6,271 & $(78.7)$ & 6,122 & $(79.6)$ & 24,805 & $(77.3)$ & $<0.001$ \\
\hline Antiarrhythmic medication & 674 & $(8.0)$ & 721 & $(9.0)$ & 694 & $(8.7)$ & 546 & $(7.1)$ & 2,635 & $(8.2)$ & $<0.001$ \\
\hline $\begin{array}{l}\text { Secondary prevention of } \\
\text { cardiovascular disease }\end{array}$ & 6,199 & $(73.5)$ & 6,063 & $(75.9)$ & 6,065 & $(76.1)$ & 5,727 & $(74.5)$ & 2,4054 & $(75.0)$ & $<0.001$ \\
\hline Other antiplatelet agents ${ }^{b}$ & 477 & $(5.7)$ & 369 & $(4.6)$ & 278 & $(3.5)$ & 263 & $(3.4)$ & 1,387 & $(4.3)$ & $<0.001$ \\
\hline Periprocedural anticoagulation & 646 & $(7.7)$ & 374 & $(4.7)$ & 326 & $(4.1)$ & 296 & $(3.8)$ & 1,642 & $(5.1)$ & $<0.001$ \\
\hline $\begin{array}{l}\text { Baseline number of emergency } \\
\text { visits/hospitalizations, mean [SD] }\end{array}$ & 1.8 & {$[3.9]$} & 1.5 & {$[3.3]$} & 1.2 & {$[2.8]$} & 1.0 & {$[2.4]$} & 1.3 & {$[3.2]$} & $<0.001$ \\
\hline \multicolumn{12}{|c|}{$\begin{array}{l}\text { aEnhanced ICD-9-CM comorbidity algorithm. }{ }^{36} \\
\text { bClopidogrel, ticlopidine, prasugrel, and ticagrelor use. } \\
\text { CCI =Charlson Comorbidity Index; ICD-9-CM=International Classification of Diseases, Ninth Revision, Clinical Modification; SD=standard deviation; } \\
\text { TTR= time-in-therapeutic range. }\end{array}$} \\
\hline
\end{tabular}

for individuals with frequent pharmacist interventions (fourth quartile: $\geq 24$ times per year) and $64.2 \%(63.8 \%-64.6 \%)$ for less frequent pharmacist interventions (second quartile: 12-16 times per year). However, lower TTRs were found for patients with the lowest number of INR monitoring (first quartiles) or pharmacist interventions, compared with the patients in the second quartile-mean (SD) TTRs: (a) 55.4\% (26.9\%) versus 64.2\% (18.6\%) for pharmacist interventions $(P<0.001)$; (b) $59.1 \%$ (26.6\%) versus 
Warfarin Management and Outcomes in Patients with Nonvalvular Atrial Fibrillation Within an Integrated Health Care System

TABLE 2 INR Monitoring, Anticoagulation Clinic Interventions, and Warfarin Dose Adjustments

\begin{tabular}{|c|c|c|c|c|c|}
\hline Measures & & Months 1-3 & Months 4-6 & Months 7-18 & Months 19-30 \\
\hline Duration for Evaluation & & 3 months & 3 months & 12 months & 12 months \\
\hline \multicolumn{6}{|l|}{ Overalla $^{a}$} \\
\hline Number of INR monitoring tests & 8.4 & $(8.5)(n=19,086)$ & $5.9 \quad(6.1)(n=22,580)$ & $18.6(20.1) \quad(n=24,583)$ & $18.8(21.2) \quad(n=19,955)$ \\
\hline Number of anticoagulation clinic interventions ${ }^{b}$ & 7.0 & $(4.8) \quad(n=19,603)$ & $4.9 \quad(3.0) \quad(n=23,424)$ & $15.3 \quad(8.9) \quad(\mathrm{n}=25,477)$ & $15.2 \quad(8.6) \quad(n=20,563)$ \\
\hline Number of dose adjustments & 4.0 & $(3.6) \quad(n=16,701)$ & $2.9 \quad(2.8)(\mathrm{n}=15,860)$ & $6.7 \quad(6.3) \quad(n=24,437)$ & $6.7 \quad(6.3) \quad(n=19,974)$ \\
\hline Days between INR monitoring & 8.7 & $(7.7) \quad(n=16,375)$ & $17.1(12.7) \quad(n=21,926)$ & $22.1 \quad(17.8) \quad(n=24,505)$ & $23.4(23.4) \quad(n=19,925)$ \\
\hline Days between interventions & 9.0 & $(7.7) \quad(n=16,332)$ & $15.9(11.0) \quad(n=21,905)$ & $21.5(15.8) \quad(n=24,945)$ & $22.3(16.0) \quad(n=20,147)$ \\
\hline $\begin{array}{l}\text { Days between INR and the next dose } \\
\text { adjustment, median (IQR) }\end{array}$ & & $(1-4)(n=15,390)$ & $1 \quad(1-4) \quad(n=15,390)$ & $1 \quad(1-3) \quad(n=22,887)$ & $1 \quad(1-3) \quad(n=18,596)$ \\
\hline \multicolumn{6}{|l|}{ New warfarin users ${ }^{a}$} \\
\hline Number of INR monitoring tests & 11.4 & $(8.7)(\mathrm{n}=11,585)$ & $6.7 \quad(6.1) \quad(n=10,941)$ & $18.1 \quad(17.4) \quad(n=11,456)$ & $17.4(16.8)$ \\
\hline Number of anticoagulation clinic interventions ${ }^{b}$ & 9.6 & $(4.0) \quad(n=12,051)$ & $5.7 \quad(3.2) \quad(n=11,433)$ & $15.3 \quad(9.1) \quad(n=11,964)$ & $14.6 \quad(8.7)$ \\
\hline Number of dose adjustments & 4.7 & $(3.7)(n=10,364)$ & $3.3 \quad(3.2) \quad(n=8,396)$ & $7.0 \quad(6.5) \quad(\mathrm{n}=11,156)$ & $6.6 \quad(6.2)$ \\
\hline Days between INR monitoring & 7.7 & $(6.2) \quad(n=11,255)$ & $15.2(11.1)(n=10,872)$ & $20.5(18.1) \quad(n=11,418)$ & $22.5(27.4)$ \\
\hline Days between interventions & 8.0 & $(6.3) \quad(n=11,631)$ & $14.3 \quad(9.6) \quad(n=10,980)$ & $19.9(15.0) \quad(n=11,606)$ & $21.2(15.6)$ \\
\hline $\begin{array}{l}\text { Days between INR and the next dose } \\
\text { adjustment, median (IQR) }\end{array}$ & & $(1-4) \quad(n=9,815)$ & $1 \quad(1-4) \quad(n=9,815)$ & $1 \quad(1-3) \quad(n=10,254)$ & $(\mathrm{n}=7,401)$ \\
\hline \multicolumn{6}{|l|}{ Experienced warfarin users $^{\mathrm{a}}$} \\
\hline Number of INR monitoring tests & & $(5.7) \quad(n=7,501)$ & $5.2 \quad(6.0) \quad(n=11,639)$ & $19.0(22.2) \quad(\mathrm{n}=13,127)$ & $19.9(24.0) \quad(n=11,232)$ \\
\hline Number of anticoagulation clinic interventions ${ }^{b}$ & & $(2.6) \quad(n=7,552)$ & $4.2 \quad(2.7) \quad(n=11,991)$ & $15.3 \quad(8.7) \quad(\mathrm{n}=13,513)$ & $15.6 \quad(8.5) \quad(n=11,535)$ \\
\hline Number of dose adjustments & 2.9 & $(3.1) \quad(n=6,337)$ & $2.5 \quad(2.2) \quad(n=7,464)$ & $6.4 \quad(6.1) \quad(n=13,281)$ & $6.8 \quad(6.3) \quad(n=1,840)$ \\
\hline Days between INR monitoring & 14.4 & $(11.8) \quad(n=5,120)$ & $19.6(14.0) \quad(n=11,054)$ & $23.5(17.3)(n=13,087)$ & $23.9(20.1) \quad(n=11,228)$ \\
\hline Days between interventions & 14.9 & $(11.5) \quad(n=4,701)$ & $17.9(12.2) \quad(n=10,925)$ & $22.8(16.4) \quad(n=13,339)$ & $23.0(16.2) \quad(n=11,381)$ \\
\hline $\begin{array}{l}\text { Days between INR and the next dose } \\
\text { adjustment, median (IQR) }\end{array}$ & & $(1-4) \quad(n=5,575)$ & $1 \quad(1-4) \quad(n=5,575)$ & $1 \quad(1-3) \quad(n=12,642)$ & $1 \quad(1-3) \quad(n=11,195)$ \\
\hline
\end{tabular}

62.9\% (18.4\%) for INR monitoring with $P<0.001$, respectively. Patients with frequent dose adjustments also had lower TTRs compared with other groups-mean (SD) TTR: 45.3\% (19.1\%) for $\geq 11$ adjustments per year versus $62.3 \%$ (18.1\%) for 4-6 dose adjustments per year $(P<0.001)$.

\section{Clinical Outcomes}

A total of 1,239 stroke or systemic embolism events were identified during 95,076 person-years (1.3 per 100 personyears), and 7,179 major bleeding events were identified during 79,648 person-years (9.0 per 100 person-years; Table 3). Seventy percent of stroke or systemic embolism events were ischemic stroke; $16 \%$ were hemorrhagic stroke; and 14\% were systemic embolism. For major bleeding events, 69\% were gastrointestinal bleeds; 29\% were other types of bleeds; and only $2 \%$ were intracranial hemorrhage.

TTR was associated with clinical outcomes regardless of frequency of INR monitoring, pharmacist interventions, or number of dose adjustments. Patients whose TTR was $<65 \%$ even with frequent pharmacist interventions ( $>16$ times per year) had a higher stroke or systemic embolism risk as compared with the reference of TTR $\geq 65 \%$ and less frequent interventions ( $\leq 16$ times per year; adjusted $\mathrm{HR}=1.94,95 \%$ $\mathrm{CI}=1.62-2.27$; Table 4). Similar results were found when we compared patients with TTR $<65 \%$ with less frequent pharmacist interventions ( $\leq 16$ times per year) with the same reference group (adjusted $\mathrm{HR}=1.91,95 \% \mathrm{CI}=1.63-2.23$ ). Patients with TTR $\geq 65 \%$ with less frequent pharmacist interventions $(\leq 16$ times per year) had similar stroke or systemic embolism risk when compared with the reference of TTR $\geq 65 \%$ and less frequent interventions ( $\leq 16$ times per year; adjusted HR $=1.10$, 95\% CI $=0.89-1.36$ ).

A linear relationship was found between the stroke or systemic embolism rates per 100 person-years and TTR quartiles: $0.89,0.94,1.27$, and 2.76 (TTR $\geq 73 \%, 61 \%-72 \%, 46 \%-60 \%$, and $<46 \%$, respectively; Table 3). Major bleeding rates tended to be inversely related to TTR; major bleeding rates per 100 person-years were $7.81,6.76,8.52$, and 15.91 for TTR $\geq 73 \%$, $61 \%-72 \%, 46 \%-60 \%$, and $<46 \%$, respectively. The high rates of stroke or systemic embolism and major bleeding were driven by the lowest TTR quartile. Controlling for baseline characteristics, the lowest quartile of TTR $(<46 \%)$ was associated with a 3 times higher risk of stroke or systemic embolism $(\mathrm{HR}=3.19,95 \% \mathrm{CI}=2.71-3.77)$ and a 2 times higher risk of 


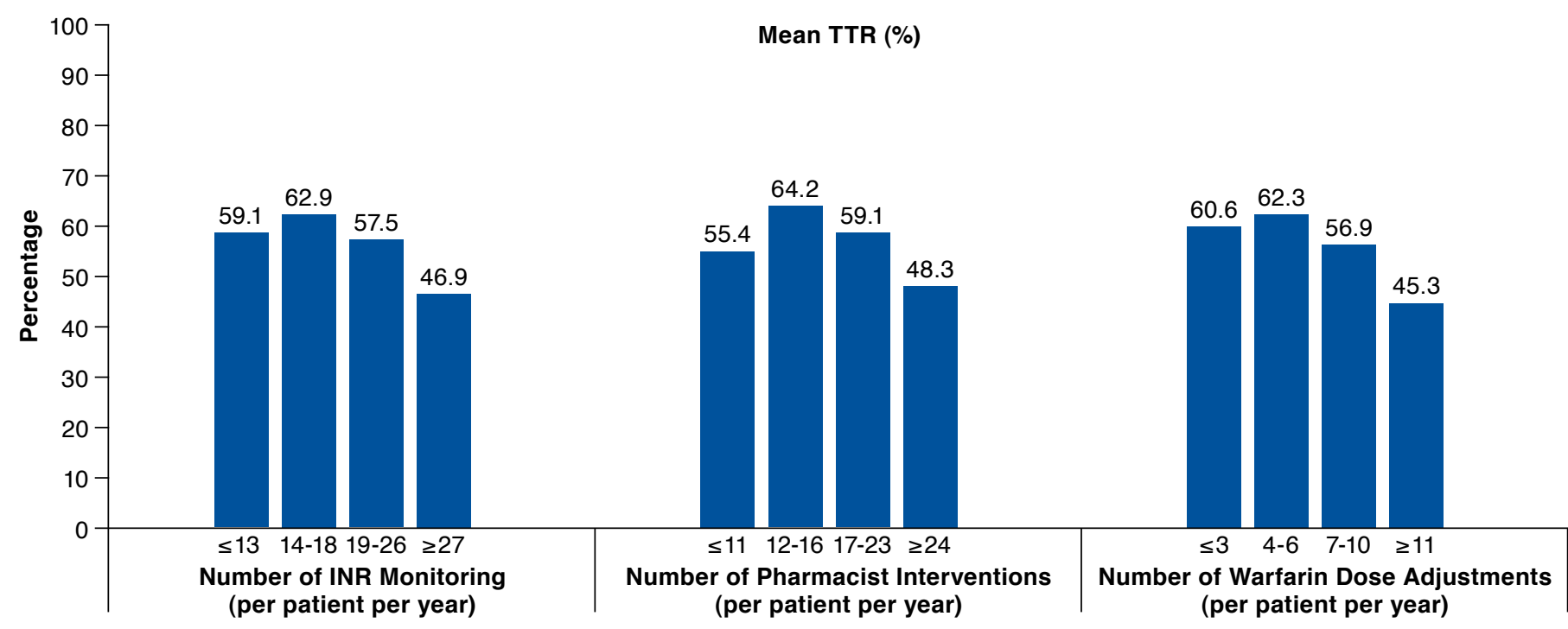

Note: The number of INR monitoring, pharmacist interventions, and warfarin dose adjustments were categorized by quartiles. The mean and standard error (error bar) of the TTRs were shown per each quartile. All pair-wise comparisons show statistically significant difference, $P<0.001$.

INR=international normalized ratio; TTR= time-in-therapeutic range.

major bleeding (HR=2.10, 95\% CI=1.96-2.24) compared with the highest TTR quartile ( $\geq 73 \%$; Table 3 ). The second lowest TTR (46\%-60\%) was associated with a 31\% increased risk of stroke or systemic embolism (HR=1.31, 95\% CI=1.11-1.56) compared with the highest TTR quartile; however, the risk of bleeds was not statistically different. Interestingly, the second highest TTR (61\%-72\%) was associated with a lower risk of bleeds ( $\mathrm{HR}=0.85,95 \% \mathrm{CI}=0.79-0.91$ ), but the risk of stroke or systemic embolism was not statistically different compared with the highest TTR.

\section{Discussion}

This study found that NVAF patients on warfarin were closely monitored and received frequent interventions from the pharmacist-led anticoagulation clinics. Clinical guidelines recommend INR testing at least weekly during initiation of warfarin therapy and at least every 4 weeks when anticoagulation is stable or allow an interval of up to 12 weeks for selected patients with extremely stable control., ${ }^{1,525}$ This study suggests that the INR monitoring tests within this integrated health care setting have been conducted as frequently as guidelines have suggested; the median days between INR tests were approximately 3 weeks. This finding is similar to the results from other studies-the median or mean interval between INR results from anticoagulation clinics was from 18.1 to 22 days..$^{10,26,27}$ As expected, more frequent INR tests and anticoagulation clinic interventions were found during the first 3 months among new warfarin users.

Once INR is out of range, clinicians either choose to observe, instruct to skip the dose, or change the maintenance dose..$^{25}$ This study investigated 1-time dose adjustments and changes in maintenance dose, since these are all active pharmacist interventions. In general, we found timely dose adjustment. Half of the time, dosing instructions were found the day after the INR laboratory test. More frequent dose adjustments were observed in the first 3 months after initiation of the therapy. However, only $63 \%$ of the patients had at least 1 dose adjustment. The $37 \%$ of patients without any dose adjustment information might have been stable patients who did not require dosing changes or the INR was at the borderline range $(9.7 \%$ is with INR 1.9 and $4 \%$ is with INR 3.1), so no dose adjustments were made by the clinician.

Yearly attrition rate was fairly low. The attrition rates increased slightly over time. These rates were lower compared with results from other studies. ${ }^{11-13}$ In this study, we assumed that patients were still on treatment if they potentially possessed warfarin prescriptions and/or their INRs were being monitored. Fang et al. (2010) found that the discontinuation rate was $26.3 \%$ during the first year of warfarin initiation, but the rate lowered to $8.0 \%$ in the second year. ${ }^{13}$ These differences are potentially because of the study population-this study 
TABLE 3 Number of Stroke or Systemic Embolism and Major Bleeding by TTRs

\begin{tabular}{|c|c|c|c|c|c|}
\hline & TTR $<46 \%$ & TTR $46 \%-60 \%$ & TTR $61 \%-72 \%$ & TTR $\geq 73 \%$ & Total \\
\hline Stroke or systemic embolism, total patients, $\mathbf{n}$ & 8,435 & 7,893 & 7,966 & 7,690 & 32,074 \\
\hline Total stroke or systemic embolism events, n (\%) & $419 \quad(5.0)$ & $315 \quad(3.9)$ & $269 \quad(3.4)$ & $236 \quad(3.1)$ & $1,239 \quad(3.9)$ \\
\hline Hemorrhagic stroke & $(0.7)$ & $(0.5)$ & $(0.7)$ & $(0.5)$ & $(0.6)$ \\
\hline Ischemic stroke & $(3.6)$ & $(2.8)$ & $(2.2)$ & $(2.2)$ & $(2.7)$ \\
\hline Systemic embolism & $(0.6)$ & $(0.7)$ & $(0.5)$ & $(0.4)$ & $(0.5)$ \\
\hline Mean [SD] follow-up, days & $\begin{array}{ll}657 & {[615]} \\
\end{array}$ & $1,137 \quad[681]$ & $1,314 \quad[677]$ & $1,253 \quad[717]$ & $1,083 \quad[722]$ \\
\hline Number of stroke or systemic embolism events per 100 person-years & 2.76 & 1.27 & 0.94 & 0.89 & 1.30 \\
\hline Adjusted HR (95\% CI), N=32,074a & $3.19(2.71-3.77)$ & $1.31(1.11-1.56)$ & $0.98(0.82-1.17)$ & Reference & \\
\hline Major bleeding, total patients, $\mathbf{n}$ & 8,575 & 7,414 & 7,353 & 7,670 & 31,012 \\
\hline Total major bleeding events, $\mathrm{n}(\%)$ & $2,083 \quad(24.3)$ & $1,717 \quad(23.2)$ & $1,594 \quad(21.7)$ & $1,785 \quad(23.3)$ & $7,179 \quad(23.1)$ \\
\hline Intracranial bleeding & $47 \quad(0.5)$ & $44 \quad(0.6)$ & $(0.4)$ & $25 \quad(0.3)$ & $(0.5)$ \\
\hline Gastrointestinal bleeding & $1,451 \quad(16.9)$ & $(15.5)$ & $1,118 \quad(15.2)$ & $1,247 \quad(16.3)$ & $(16.0)$ \\
\hline Other types of bleeding & $585 \quad(6.8)$ & $(7.1)$ & $444 \quad(6.0)$ & $(6.7)$ & 2,068 \\
\hline Mean [SD] follow-up, days & $558 \quad[561]$ & $992[660]$ & $1,171 \quad[682]$ & 1,088 & $938 \quad[697]$ \\
\hline Number of major bleeding events per 100 person-years & 15.91 & 8.52 & \begin{tabular}{|l|}
6.76 \\
\end{tabular} & 7.81 & 9.01 \\
\hline Adjusted HR (95\% CI), N=31,012b & $2.10(1.96-2.24)$ & $1.05(0.98-1.12)$ & $0.85(0.79-0.91)$ & Reference & \\
\hline \multicolumn{6}{|c|}{$\begin{array}{l}\text { aAdjusted for age; sex; racelethnicity; warfarin start in } 2 \text { months; baseline conditions (myocardial infarction); baseline number of emergency visits/hospitalizations; baseline } \\
\text { medication use (anti-arrythmic medication, heart rate control, periprocedural anticoagulation, and previous warfarin use); CHADS }{ }_{2} \text { scores; and CCI scores. } \\
\text { bAdjusted for age; sex; racelethnicity; warfarin start in } 2 \text { months; baseline conditions (malignancy, asthma, peripheral vascular disease, bleed, dementia, fall, and cardiac } \\
\text { myopathy); CHADS } 2 \text { scores; and CCI scores. } \\
\text { CCI=Charlson Comorbidity Index; CI= confidence interval; HR=hazard ratio; SD=standard deviation; TTR= time-in-therapeutic range. }\end{array}$} \\
\hline
\end{tabular}

investigated attrition rates for the warfarin-naive and warfarinexperienced patients in NVAF, whereas Fang et al. only focused on warfarin-naive patients. Moreover, the definition of discontinuation varies. Our study applied 80 days of grace period from the last warfarin or INR laboratory testing, whereas the Fang et al. study defined discontinuation as $\geq 180$ consecutive days off warfarin. ${ }^{13}$ Another potential reason could be because of the improved warfarin management of the anticoagulation clinics. Other recent studies investigating claims data in the United States reported higher discontinuation rates up to $43 \%$ within 1 year after the warfarin initiation. ${ }^{11}$

Although our study's findings reflect close monitoring patterns for warfarin patients managed by pharmacist-managed anticoagulation clinics, the TTR ranges were comparable with other studies conducted in the United States. This study's median TTR $(61 \%)$ is similar to the mean TTR of $61 \%$ from the experienced warfarin patients in the Veterans Health Administration system and to the mean TTR of $67 \%$ from the U.S. anticoagulation management records, which contain approximately 400,000 patient records receiving anticoagulation therapy. ${ }^{22,28}$ The TTRs for the total or experienced warfarin patients were slightly higher than the TTRs from the warfarin naive cohort ${ }^{29}$; however, these ranges would not be considered optimal. These results, together with current literature, suggest that it is still challenging to maintain appropriate TTR ranges even if patients are closely monitored.

Our study findings regarding TTRs by warfarin management patterns also suggest a challenging subpopulation even with close monitoring. The mean TTR was only $45 \%-48 \%$ for the top $25 \%$ of patients who required the highest number of INR monitoring, interventions, or dose adjustments. These patients received approximately 1.5 to 2 times more INR monitoring or pharmacist interventions compared with the average patient, but TTRs were still the lowest. Those challenging patients with suboptimal TTRs $(<65 \%)$ and frequent pharmacist interventions eventually developed more stroke or systemic embolism events. These patients may be good candidates for different treatment options. Although the specific data are not presented here, baseline characteristics of the patients with TTRs $<65 \%$, compared with TTRs $\geq 65 \%$ among the patients who received frequent interventions, suggest that patients who had a higher number of comorbidities, a higher percentage of emergency visits or hospitalizations, or who were nonHispanic black would more likely find it difficult to maintain optimal TTR. National guidelines suggest consideration of one of the direct oral anticoagulants (DOACs) if patients are unable to maintain therapeutic INR levels with warfarin, ${ }^{30}$ and these patients could be good candidates for DOAC. Future studies to further investigate these challenging patients and to evaluate outcomes from different treatment options would be beneficial. On the other hand, there were also groups of patients whose TTRs were $\geq 65 \%$ and who did not require frequent interventions. These stable patients could still be good candidates for continuing warfarin therapy.

This analysis shows another group of patients with suboptimal TTR and less frequent INR monitoring or pharmacist 
TABLE 4 Stroke or Systemic Embolism Outcomes by Pharmacist Interventions and TTRs

\begin{tabular}{|c|c|c|c|c|}
\hline & Patients, $\mathbf{n}$ & $\begin{array}{l}\text { Stroke or Systemic } \\
\text { Embolism, } \mathbf{n}\end{array}$ & $\begin{array}{l}\text { Stroke or Systemic } \\
\text { Embolism Rate, } \\
100 \text { Person-Years }\end{array}$ & $\begin{array}{l}\text { Adjusted HR } \\
(95 \% \mathrm{CI})^{\mathrm{a}}\end{array}$ \\
\hline TTR $<65 \%$ and frequent management ${ }^{b}$ & 10,837 & 452 & 1.88 & $1.94(1.66-2.27)$ \\
\hline TTR $<65 \%$ and less frequent management & 8,204 & 385 & 1.54 & $1.91(1.63-2.23)$ \\
\hline TTR $\geq 65 \%$ and frequent management & 4,853 & 132 & 1.02 & $1.10(0.89-1.36)$ \\
\hline TTR $\geq 65 \%$ and less frequent management & 8,180 & 270 & 0.82 & Reference \\
\hline Total & 32,704 & 1,239 & 1.30 & \\
\hline \multicolumn{5}{|c|}{$\begin{array}{l}\text { aAdjusted for age; sex; racelethnicity; baseline conditions (stroke/trasient ischemic attack and dementia); baseline number of emergency visits/hospitalizations; baseline } \\
\text { medication use (anti-arrythmic medication, heart rate control, and periprocedural anticoagulation); and } C_{2} \mathrm{ADS}_{2} \text { scores. } \\
\text { bFrequent management was defined by number of pharmacist interventions (pharmacists contact with patients, mostly through telephone counseling) }>16 \text { times per year } \\
\text { (above median). } \\
\text { CI= confidence interval; HR=hazard ratio; TTR= time-in-therapeutic range. }\end{array}$} \\
\hline
\end{tabular}

interventions. While not studied, non-adherence or nonpersistence could in part explain the low TTRs. This group of patients experienced higher stroke/SE events compared to other group of patients. For this group, different management strategies to improve adherence to therapy or management protocols should be considered as a first step, and may consider switching to different agents.

Consistent with other findings, ${ }^{31-35}$ TTR was shown to be a good intermediate predictor for stroke or systemic embolism and major bleeding outcomes. These findings are consistent regardless of the frequency of pharmacist interventions. Patients with low TTR levels showed higher likelihood of developing more stroke or systemic embolism and bleeding. Baseline characteristics based on TTR strata suggest that the lowest TTR group had more comorbidities and more history of bleeding and falls, which increases likelihood of recurrent bleeds. The lowest TTR group represented $26 \%$ of the patients in this study, suggesting that a significant number of NVAF patients struggle with warfarin management, which exposes them to higher risk of strokes and bleeding events. As the results have shown, about half of these patients were not able to maintain optimal TTR levels even with frequent pharmacist interventions. Future studies will be necessary to better understand the reasons for low TTR, which include nonadherent behaviors, financial limitations, and patient preferences. Base on this, individualized strategies to improve outcomes of these high-risk patients are needed.

\section{Limitations}

This study has several limitations, many of which are consistent with the nature of retrospective, observational studies, including reliance on the accuracy and availability of the data. We developed an NLP algorithm to extract warfarin dosing information from clinical notes. Although randomly selected records were validated, we were not able to individually validate all of the selected records and therefore the sensitivity of the algorithm.
This study analyzed anticoagulation clinic intervention data from an EMR system, which by design relies heavily on clinician documentation. The definition of warfarin discontinuation as 80 days of grace was newly applied, so this definition was also not validated. Because of the retrospective nature of this study, we were not able to capture all of the factors associated with stroke or bleeding events. Statistical methodologies were applied to control for observed characteristics, but we were not able to control for unobservable factors such as patient preferences or clinical judgment. Generalizability is another limitation, since this study was only conducted in 1 managed care setting.

Despite these limitations, this study has several strengths. This study is one of the few that describe warfarin management patterns in clinical practice using a rich data source in a large cohort. Over 30,000 warfarin patients were followed for a median of 3.8 years. Anticoagulation clinic data from the EMR were extracted, and a newly developed NLP algorithm was applied. The warfarin management patterns, as well as clinical outcomes, were investigated in a large, ethnically diverse population.

\section{Conclusions}

$\overline{\text { Close monitoring with timely warfarin dose adjustments and }}$ low attrition rates were found in patients with NVAF managed by pharmacist-led anticoagulation clinics in an integrated health care system. However, there were still a substantial number of challenging patients whose TTRs were suboptimal, despite a higher number of pharmacist interventions. These patients eventually experienced significantly more stroke or systemic embolism and bleeding events. Maintaining an appropriate TTR is important to maximize stroke or systemic embolism prevention benefits from warfarin therapy while minimizing bleeding events. New individualized treatment and/or management strategies for NVAF patients who are not able to reach optimal therapeutic ranges are necessary to improve outcomes. 


\section{Authors}

JAEJIN AN, BPharm, PhD, Department of Pharmacy Practice and Administration, College of Pharmacy, Western University of Health Sciences, Pomona, California. FANG NIU, MS, Drug Information Services; NAZIA RASHID, PharmD, MS, Drug Information Services; and PAUL T. LE, PharmD, Medication Therapy Management, Kaiser Permanente Southern California, Downey. CHENGYI ZHENG, PhD, Research and Evaluation, Kaiser Permanente Southern California, Pasadena. ROBERT A. MENDES, $M D$, and DIANA DILLS, MD, North America Medical Affairs, Pfizer, New York, New York. LIEN VO, PharmD, MPH; PRIANKA SINGH, PharmD; AMANDA BRUNO, PhD, MPH; and GUSTAVUS ARANDA, JR., PharmD, MS, Health Economic Outcomes Research, Bristol-Myers Squibb, Plainsboro, New Jersey. DANIEL T. LANG, MD, Los Angeles Medical Center, The Permanente Medical Group, Kaiser Permanente Southern California, Los Angeles, and KRISTIN P. JAZDZEWSKI, PharmD, San Diego Medical Center, Kaiser Permanente Southern California, San Diego.

AUTHOR CORRESPONDENCE: JaeJin An, BPharm, PhD, Department of Pharmacy Practice and Administration, College of Pharmacy, Western University of Health Sciences, 309 E. Second St., Pomona, CA 91766. Tel.: 909.469.8778; E-mail: jan@westernu.edu.

\section{DISCLOSURES}

This research and manuscript were funded by Bristol-Myers Squibb Company and Pfizer. Authors from Bristol-Myers Squibb Company and Pfizer participated in the design of the study, interpretation of the data, review/revision of the manuscript, and approval of the final version of the manuscript. An received a grant for research support from Bristol-Myers Squibb/Pfizer. Niu, Rashid, and Zheng received a grant from Bristol-Myers Squibb/Pfizer to their institutions for salary reimbursement. Vo, Singh, and Aranda are employed by Bristol-Myers Squibb; Bruno was employed by Bristol-Myers Squibb at the time of this study. Mendes and Dills are employed by Pfizer, and Mendes was a member of the Pfizer Cardiovascular and Metabolic Field Medical Team during the time of this study. Lang, Jazdzewski, and Le have no known conflicts of interest to report.

Study concept and design were contributed primarily by An and Rashid, along with the other authors. Niu took the lead in data collection, along with Zheng, and data interpretation was performed by An, along with Mendes and Dills, with assistance from the other authors. The manuscript was written by An and revised by Mendes, Dills, Vo, Singh, Bruno, and Aranda, along with Lang, Le, and Jazdezewski.

Part of this study's findings was presented at the CHEST 2015 Annual Meeting in Montreal, Canada, on October 28, 2015.

\section{REFERENCES}

1. Fuster V, Ryden LE, Cannom DS, et al. 2011 ACCF/AHA/HRS focused updates incorporated into the ACC/AHA/ESC 2006 guidelines for the management of patients with atrial fibrillation: a report of the American College of Cardiology Foundation/American Heart Association Task Force on practice guidelines. Circulation. 2011;123(10):e269-367.

2. Patel MR, Mahaffey KW, Garg J, et al. Rivaroxaban versus warfarin in nonvalvular atrial fibrillation. N Engl J Med. 2011;365(10):883-91

3. Albers GW, Diener HC, Frison L, et al. Ximelagatran vs warfarin for stroke prevention in patients with nonvalvular atrial fibrillation: a randomized trial. JAMA. 2005;293(6):690-98.
4. Agarwal S, Hachamovitch R, Menon V. Current trial-associated outcomes with warfarin in prevention of stroke in patients with nonvalvular atrial fibrillation: a meta-analysis. Arch Intern Med. 2012;172(8):623-31.

5. Ansell J, Hirsh J, Hylek E, et al. Pharmacology and management of the vitamin K antagonists: American College of Chest Physicians EvidenceBased Clinical Practice Guidelines (8th Edition). Chest. 2008;133(6 Suppl): 160S-198S.

6. Young S, Bishop L, Twells L, Dillon C, Hawboldt J, O'Shea P. Comparison of pharmacist managed anticoagulation with usual medical care in a family medicine clinic. BMC Fam Pract. 2011;12:88.

7. van Walraven C, Jennings A, Oake N, Fergusson D, Forster AJ. Effect of study setting on anticoagulation control: a systematic review and metaregression. Chest. 2006;129(5):1155-66.

8. Entezari-Maleki T, Dousti S, Hamishehkar H, Gholami K. A systematic review on comparing 2 common models for management of warfarin therapy; pharmacist-led service versus usual medical care. J Clin Pharmacol. 2016;56(1):24-38

9. Wilson SJ, Wells PS, Kovacs MJ, et al. Comparing the quality of oral anticoagulant management by anticoagulation clinics and by family physicians: a randomized controlled trial. CMAJ. 2003;169(4):293-98.

10. Bungard TJ, Gardner L, Archer SL, et al. Evaluation of a pharmacistmanaged anticoagulation clinic: improving patient care. Open Med. 2009;3(1):e16-21.

11. Spivey CA, Qiao Y, Liu X, et al. Discontinuation/interruption of warfarin therapy in patients with nonvalvular atrial fibrillation. J Manag Care Spec Pharm. 2015;21(7):596-606. Available at: http://www.jmcp.org/doi/10.18553/ jmcp.2015.21.7.596.

12. Nelson WW, Song X, Coleman CI, et al. Medication persistence and discontinuation of rivaroxaban versus warfarin among patients with nonvalvular atrial fibrillation. Curr Med Res Opin. 2014;30(12):2461-69.

13. Fang MC, Go AS, Chang Y, et al. Warfarin discontinuation after starting warfarin for atrial fibrillation. Circ Cardiovasc Qual Outcomes. 2010;3(6):624-31.

14. Baker WL, Cios DA, Sander SD, Coleman CI. Meta-analysis to assess the quality of warfarin control in atrial fibrillation patients in the United States. J Manag Care Pharm. 2009;15(3):244-52. Available at: http://www.jmcp.org/ doi/10.18553/jmcp.2009.15.3.244.

15. National Clinical Guideline Centre. Atrial fibrillation: the management of atrial fibrillation. Clinical guideline methods, evidence and recommendations. June 2014. Available at: https://www.nice.org.uk/guidance/cg180/evidence/atrial-fibrillation-update-full-guideline-243739981. Accessed April 14, 2017.

16. Jha AK. The promise of electronic records: around the corner or down the road? JAMA. 2011;306(8):880-81.

17. Carrell DS, Cronkite D, Palmer RE, et al. Using natural language processing to identify problem usage of prescription opioids. Int J Med Inform. 2015;84(12):1057-64.

18. Murff HJ, FitzHenry F, Matheny ME, et al. Automated identification of postoperative complications within an electronic medical record using natural language processing. JAMA. 2011;306(8):848-55

19. FitzHenry F, Murff HJ, Matheny ME, et al. Exploring the frontier of electronic health record surveillance: the case of postoperative complications. Med Care. 2013;51(6):509-16.

20. Zheng CY, Rashid N, Wu YL, et al. Using natural language processing and machine learning to identify gout flares from electronic clinical notes. Arthritis Care Res (Hoboken). 2014;66(11):1740-48.

21. Zheng CY, Rashid N, Koblick R, An J. Medication extraction from electronic clinical notes in an integrated health system: a study on aspirin use in patients with nonvalvular atrial fibrillation. Clin Ther. 2015;37(9):2048-58. 
22. Rose AJ, Hylek EM, Ozonoff A, Ash AS, Reisman JI, Berlowitz DR. Patient characteristics associated with oral anticoagulation control: results of the Veterans AffaiRs Study to Improve Anticoagulation (VARIA). J Thromb Haemost. 2010;8(10):2182-91.

23. Rosendaal FR, Cannegieter SC, van der Meer FJ, Briet E. A method to determine the optimal intensity of oral anticoagulant therapy. Thromb Haemost. 1993;69(3):236-39.

24. De Caterina R, Husted S, Wallentin L, et al. Vitamin K antagonists in heart disease: current status and perspectives (Section III). Position paper of the ESC Working Group on Thrombosis-Task Force on Anticoagulants in Heart Disease. Thromb Haemost. 2013;110(6):1087-107.

25. Holbrook A, Schulman S, Witt DM, et al. Evidence-based management of anticoagulant therapy: Antithrombotic Therapy and Prevention of Thrombosis, 9th ed: American College of Chest Physicians Evidence-Based Clinical Practice Guidelines. Chest. 2012;141(2 Suppl):e152S-184S.

26. Witt DM, Sadler MA, Shanahan RL, Mazzoli G, Tillman DJ. Effect of a centralized clinical pharmacy anticoagulation service on the outcomes of anticoagulation therapy. Chest. 2005;127(5):1515-22.

27. Stewart A, Ganguli A, FitzGerald R, Pirmohamed M. Variation in warfarin prescribing and dosing in the UK: a national survey of anticoagulation clinics. J Clin Pharm Ther. 2015;40(4):466-471.

28. Nelson WW, Desai S, Damaraju CV, et al. International normalized ratio stability in warfarin-experienced patients with nonvalvular atrial fibrillation. Am J Cardiovasc Drugs. 2015;15(3):205-11.

29. An J, Niu F, Lang DT, et al. Stroke and bleeding risk associated with antithrombotic therapy for patients with nonvalvular atrial fibrillation in clinical practice. J Am Heart Assoc. 2015;4(7). pii: e001921.
30. January CT, Wann LS, Alpert JS, Calkins H, Cigarroa JE, Cleveland JC Jr. 2014 AHA/ACC/HRS guideline for the management of patients with atrial fibrillation: a report of the American College of Cardiology/American Heart Association Task Force on Practice Guidelines and the Heart Rhythm Society. J Am Coll Cardiol. 2014;64(21):e1-76.

31. Wallentin L, Yusuf S, Ezekowitz MD, et al. Efficacy and safety of dabigatran compared with warfarin at different levels of international normalised ratio control for stroke prevention in atrial fibrillation: an analysis of the RE-LY trial. Lancet. 2010;376(9745):975-83.

32. Connolly SJ, Pogue J, Eikelboom J, et al. Benefit of oral anticoagulant over antiplatelet therapy in atrial fibrillation depends on the quality of international normalized ratio control achieved by centers and countries as measured by time in therapeutic range. Circulation. 2008;118(20):2029-37.

33. White HD, Gruber M, Feyzi J, et al. Comparison of outcomes among patients randomized to warfarin therapy according to anticoagulant control: results from SPORTIF III and V. Arch Intern Med. 2007;167(3):239-45.

34. Piccini JP, Hellkamp AS, Lokhnygina Y, et al. Relationship between time in therapeutic range and comparative treatment effect of rivaroxaban and warfarin: results from the ROCKET AF trial. J Am Heart Assoc. 2014;3(2):e000521.

35. Gallego P, Vilchez JA, Lane DA. Apixaban compared with warfarin for stroke prevention in atrial fibrillation: implications of time in therapeutic range. Circulation. 2013;127(22):2163-65.

36. Quan H, Sundararajan V, Halfon P. Coding algorithms for defining comorbidities in ICD-9-CM and ICD-10 administrative data. Med Care. 2005;43(11):1130-39. 


\section{APPENDIX A Definition of Variables}

\begin{tabular}{|c|c|c|}
\hline Criteria & Variable & Definition (ICD-9-CM or CPT Code) \\
\hline \multirow{5}{*}{$\begin{array}{l}\text { Exclusion } \\
\text { criteria }\end{array}$} & AF ablation & $37.34,37.33,93650,93651,93652$ \\
\hline & $\begin{array}{l}\text { Cardioversion procedure valvular repair or } \\
\text { replacement }\end{array}$ & $\begin{array}{l}92960,92961,99.61,33405,33420,33422,33425,33426,33427,33430,33496, \\
35.01-35.02,35.11-35.12,35.21-35.24, \mathrm{~V} 42.2, \mathrm{~V} 43.3\end{array}$ \\
\hline & Valvular diseases & $394 . x x, 396 . x x, 746.5$ \\
\hline & Hyperthyroidism & 242.9 \\
\hline & Evidence of pregnancy & V22.x, pregnancy EMR table \\
\hline \multirow[t]{11}{*}{ Outcome } & Stroke or systemic embolism & All stroke or systemic embolism \\
\hline & Ischemic stroke & Primary hospital discharge record: $433 . x 1,434 . x 1,436$ \\
\hline & Hemorrhagic stroke & Primary hospital discharge record: 430,431 \\
\hline & Systemic embolism & Primary hospital discharge record: 444.0, 444.1, 444.2x, 444.8x, 444.9, 557.x, 593.81 \\
\hline & Major bleed & $\begin{array}{l}\text { A bleeding event will be defined as major if it was an intracranial bleed or any other } \\
\text { bleed that was associated with the following: inpatient care (primary and secondary } \\
\text { diagnosis of major bleed), blood transfusion of } 2 \text { or more units of whole blood or red } \\
\text { blood cells, decreased hemoglobin or hematocrit of } 2 \mathrm{~g} / \mathrm{dL} \text { or more, physician guided } \\
\text { medical or surgical treatment, or death. }\end{array}$ \\
\hline & $\mathrm{ICH}$ & Primary or secondary hospital discharge record: $432 . x$ \\
\hline & & $\begin{array}{l}\text { Exclude ICH associated with a concomitant discharge diagnosis of major trauma } \\
(852.1,852.3,852.5 \text {, and 853.1) }\end{array}$ \\
\hline & GI bleeding & $\begin{array}{l}\text { Primary or secondary hospital discharge record: } 530.21,530.7,530.82,531.0 \mathrm{x}, \\
531.2 \mathrm{x}, 531.4 \mathrm{x}, 531.6 \mathrm{x}, 532.0 \mathrm{x}, 532.2 \mathrm{x}, 532.31,532.4 \mathrm{x}, 532.6 \mathrm{x}, 534.0 \mathrm{x}, 534.2 \mathrm{x}, \\
534.4 \mathrm{x}, 534.6 \mathrm{x}, 535 . \mathrm{x} 1,537.83,537.84,537.89,562.02,562.03,562.12,562.13, \\
568.81,569.3,569.69,569.85,577.8,578 \mathrm{x}, 580.9,596.7,596.8,599.7 \mathrm{x}\end{array}$ \\
\hline & $\begin{array}{l}\text { Other bleeding (e.g., intraspinal, pericardial, } \\
\text { intra-articular, and intramuscular) }\end{array}$ & $\begin{array}{l}\text { Primary or secondary hospital discharge record: } 255.41,423.0,455.2,455.5,455.8, \\
456.0,456.2 .456 .8,459.0,719.1 \mathrm{x}, 784.7,784.8,785.59,786.3,853.0 \mathrm{x}\end{array}$ \\
\hline & Others & To define major bleeding \\
\hline & $\begin{array}{l}\text { Physician-guided medical or surgical } \\
\text { treatment }\end{array}$ & $\begin{array}{l}\text { From primary or secondary hospital discharge record: } 10140,10160,11740,21501, \\
21502,23030,23930,25028,26990,27301,27603,30000,30020,30901,30903, \\
30905,30906,31238,32110,32654,32658,33020,40800,40801,41000,41005, \\
41006,41007,41008,41009,41015,41016,41017,41018,41800,42960,42961, \\
42962,42970,42971,42972,43227,43255,43460,43501,44366,44378,44391, \\
45317,45334,45382,46614,47350,47360,47361,47362,52606,54700,57023, \\
57180,61108,61154,61156,61312,61313,61314,61315,61322,61323,65930, \\
69000,69005,91100 \\
\text { ICD procedure codes: } 44.43,44.44,44.49\end{array}$ \\
\hline \multirow[t]{14}{*}{ Covariates } & Congestive heart failure & $428 . x, 429 . x$ \\
\hline & Hypertension & 401.x, 402.x, 403.x, 404.x, 405.x \\
\hline & Diabetes mellitus & $250 . \mathrm{x}$ \\
\hline & Stroke or transient ischemic attack & 433.x1, 434.x1, 435.x, 436 (in hospital or emergency room visit records) \\
\hline & Peripheral vascular disease & $443 . \mathrm{x}$ \\
\hline & Liver cirrhosis & $571.2,571.5$, or 571.6 \\
\hline & Cardiomyopathy & $425 . \mathrm{x}$ \\
\hline & Dementia & $290 . x x, 294.1 x$ \\
\hline & Bleed & $\begin{array}{l}530.21,530.7,530.82,531.0 x, 531.2 x, 531.4 x, 531.6 x, 532.0 x, 532.2 x, 532.31,532.4 x, \\
532.6 x, 534.0 x, 534.2 x, 534.4 x, 534.6 x, 535 . x 1,537.83,537.84,537.89,562.02, \\
562.03,562.12,562.13,568.81,569.3,569.69,569.85,577.8,578 . x, 580.9,596.7, \\
596.8,599.7 x, 255.41,423.0,455.2,455.5,455.8,456.0,456.2 .456 .8,459.0,719.1 x, \\
784.7,784.8,785.59,786.3,853.0 x\end{array}$ \\
\hline & Myocardial infarction & 410.x (primary hospital discharge) \\
\hline & Mechanical fall & E880-E888 (in hospital or emergency room visit records) \\
\hline & Asthma/COPD/pulmonary embolism & 493.x, 491.x, 492.x, 496.x, 415.1x, 416.2 \\
\hline & Drug/alcohol dependence & $303 . x, 304 . x$ \\
\hline & Malignancy & $\begin{array}{l}140.0-149.9,150.0-159.9,160.0-165.9,170.0-170.9,171.0-171.9,172.0-172.9,173.0- \\
173.9,174.0-175.9,176.0-176.9,179,180.0-180.9,181,182.0-183.9,184.0-184.9, \\
186.0-187.9,188.0-188.9,189.0-189.9,190.1-190.9,191.0-191.9,192.0-192.9,193, \\
194.0-194.9,195.0-195.8,196.0-198.89,199.0-1599.2,200.00-202.98,203.00-203.02, \\
203.10-203.12,209.0-209.3,235.0-235.9,236.0-236.4,236.6-236.91,237.0-238.3\end{array}$ \\
\hline
\end{tabular}




\section{APPENDIX A Definition of Variables (continued)}

\begin{tabular}{|c|c|c|}
\hline Criteria & Variable & Definition (ICD-9-CM or CPT Code) \\
\hline \multirow[t]{6}{*}{ Medication } & Warfarin & GPI code: $77204030002010,77204030002005,77204030000305$ \\
\hline & $\begin{array}{l}\text { Periprocedural anticoagulation (heparin, bival- } \\
\text { rudin, and low-molecular-weight heparin) }\end{array}$ & GPI class code: 8310 \\
\hline & $\begin{array}{l}\text { Antiarrythmic medications (quinidine, procain- } \\
\text { amide, disopyramide, propafenone, flecainide, } \\
\text { amiodaron, dofetilide, and ibutilide, dronedarone) }\end{array}$ & GPI class code: $3510,3520,3530,3540$ \\
\hline & Clopidogrel, ticlopidine, and prasugrel, ticagrelor & GPI code: 85158020100320,85158080100320 \\
\hline & $\begin{array}{l}\text { Heart rate control medications: beta-blocker, } \\
\text { calcium channel blocker, Digoxin }\end{array}$ & GPI class code: $3120,3310,3320,3330,34$ \\
\hline & $\begin{array}{l}\text { Secondary prevention medications (statins, } \\
\text { angiotensin-converting engyme inhibitors, and } \\
\text { angiotensin receptor blockers) }\end{array}$ & GPI class code: $3610,3610,3615,3699,3940$ \\
\hline
\end{tabular}

$A F=$ atrial fibrillation; $C O P D=$ chronic obstructive pulmonary disease; $C P T=$ Current Procedural Terminology; GI = gastrointestinal; GPI = Generic Product Identifier; ICD-9-CM = International Classification of Diseases, Ninth Revision, Clinical Modification; ICH =intracerebral hemorrhage.

\begin{tabular}{|c|c|c|c|c|c|}
\hline \multicolumn{6}{|c|}{ APPENDIX B Warfarin Attrition Rate by Year } \\
\hline Year & $\begin{array}{l}\text { Total Warfarin Patients } \\
\text { (A) }\end{array}$ & $\begin{array}{c}\text { Disenrolled/Completed } \\
\text { Follow-up } \\
\text { (B) }\end{array}$ & $\begin{array}{l}\text { Remained in Cohort } \\
\text { (A-B) }\end{array}$ & $\begin{array}{c}\text { Continuously on } \\
\text { Warfarin } \\
\text { (D) } \\
\%=(D) \div(\text { A }-B) \times 100 \%\end{array}$ & $\begin{array}{c}\text { Discontinued } \\
\text { Warfarin } \\
(\mathrm{E}) \\
\%=(\mathrm{E}) \div(\mathrm{A}-\mathrm{B}) \times 100 \% \\
\end{array}$ \\
\hline End of year 1 & 32,074 & 8,872 & 23,202 & $22,427(96.7)$ & $775 \quad(3.3)$ \\
\hline End of year 2 & 23,202 & 5,114 & 18,088 & $17,336(95.8)$ & $(4.2)$ \\
\hline End of year 3 & 18,088 & 3,894 & 14,194 & $13,511 \quad(95.2)$ & $683 \quad(4.8)$ \\
\hline End of year 4 & 14,194 & 3,475 & 10,719 & $10,140 \quad(94.6)$ & $579 \quad(5.4)$ \\
\hline End of year 5 & 10,719 & 3,818 & 6,901 & $6,463 \quad(93.7)$ & $(6.3)$ \\
\hline
\end{tabular}

